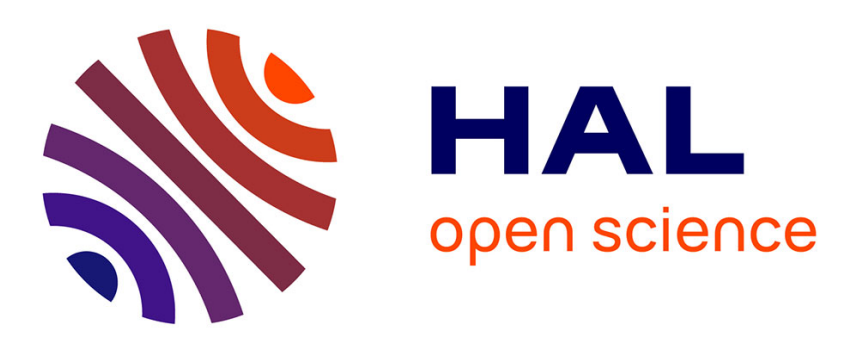

\title{
Mantle weakening and strain localization: Implications for the long-term strength of the continental lithosphere
}

\author{
Jacques Précigout, Frédéric Gueydan
}

\section{To cite this version:}

Jacques Précigout, Frédéric Gueydan. Mantle weakening and strain localization: Implications for the long-term strength of the continental lithosphere. Geology, 2009, 37 (2), pp.147-150. 10.1130/G25239A.1 . insu-00377275

\section{HAL Id: insu-00377275 \\ https://hal-insu.archives-ouvertes.fr/insu-00377275}

Submitted on 21 Apr 2009

HAL is a multi-disciplinary open access archive for the deposit and dissemination of scientific research documents, whether they are published or not. The documents may come from teaching and research institutions in France or abroad, or from public or private research centers.
L'archive ouverte pluridisciplinaire HAL, est destinée au dépôt et à la diffusion de documents scientifiques de niveau recherche, publiés ou non, émanant des établissements d'enseignement et de recherche français ou étrangers, des laboratoires publics ou privés. 


\title{
Mantle weakening and strain localization: implications for the long-term strength of the continental lithosphere
}

\author{
Jacques Précigout and Frédéric Gueydan \\ Géosciences Rennes, Université de Rennes 1, CNRS UMR 6118, 35042 Rennes, France \\ Revised the $2^{\text {nd }}$ of September 2008 ; Accepted the $8^{\text {th }}$ of October 2008.
}

\begin{abstract}
Mechanics of the continental lithosphere require the presence of a high strength uppermost mantle that defines the "jelly sandwich" model for lithosphere strength layering. However, in deforming regions, growing numbers of geological and geophysical data predict a sub-Moho mantle strength lower than the crustal strength, or a "crème brûlée" model. To reconcile these two opposite views of lithosphere strength layering, we account for a new olivine rheology, which could promote some weakening during dynamic grain size reduction that enhances the Grain Boundary Sliding. We performed a one-dimensional numerical model of a deforming rock in order to quantify strain localization due to this weakening rheology. Strain localization occurs at temperatures lower than $800^{\circ} \mathrm{C}$ and reaches a maximum at $610{ }^{\circ} \mathrm{C}$, increasing the strain rate from $10^{-15}$ to $>10^{-13} \mathrm{~s}^{-1}$. These results imply the existence of a sub-Moho ductile localizing mantle on a lithosphere scale, which occurs at Moho temperatures lower than $800{ }^{\circ} \mathrm{C}$. Also, the localizing degree of this ductile mantle increases with decreasing Moho temperatures down to $550{ }^{\circ} \mathrm{C}$. Such a ductile localizing mantle could therefore promote large strain localization during lithosphere deformation, like the brittle mantle that is commonly assumed in the "jelly sandwich" model. Furthermore, the long-term deformation $\left(\geq 10^{6} \mathrm{yr}\right)$ of the ductile localizing mantle could change the lithosphere strength layering from "jelly sandwich" to "crème brûlée" in response to the grain boundary sliding-induced weakening in mantle shear zones.
\end{abstract}

Keywords: Lithosphere rheological layering; Mantle strength; Dynamic recrystallization; Grain boundary sliding. 


\section{INTRODUCTION}

Numerous studies have dealt with rheological layering of the continental lithosphere and its consequences for lithosphere-scale deformations. Both the extrapolation of experimental data at the lithosphere scale (Brace and Kohlstedt, 1980) and studies on the mechanic of the lithosphere (Ranalli and Murphy, 1987; Brun, 2001; Handy and Brun, 2004; Gueydan et al. 2008) have implied a rheological layering, which superposes from top to bottom: a high strength brittle crust, a ductile crust, a high strength brittle/ductile uppermost mantle and a ductile upper mantle. This so-called "jelly sandwich" model of lithosphere strength is required to form both a narrow continental rift (Buck, 1991) and a mountain belt (Burov and Watts, 2006) and to explain the large elastic thickness beneath cratons (Burov and Diament, 1995). However, in deforming regions, the rare occurrence of mantle earthquakes (Maggi et al., 2000) and the weak mantle viscosity estimated from post-seismic data (Thatcher and Pollitz, 2008) do not fit the "jelly sandwich" model, leading some to argue that continental lithosphere strength resides only in the crust and not in the mantle (Maggi et al., 2000; Jackson, 2002). This so-called "crème brûlée" model of lithosphere strength concerns numerous deforming regions, regardless of the tectonic setting. Thus, a largescale deformation seems to significantly reduce the strength of the lithospheric mantle. In relation to that, the "jelly sandwich" strength profile predicts a brittle mantle in some conditions (Brace and Kolhstedt, 1980), which cannot account for a large change of strength in the continental mantle and hence, could so not explain the drop in strength that should occur during deformation. In this study, we assumed an entirely ductile uppermost mantle (fig.1A) that requires, nonetheless, the occurrence of a strain-related ductile weakening mechanism.

Rutter and Brodie (1988) suggested that tectonic grain size reduction could strongly affect the lithosphere rheological layering. Drury et al. (1991) argued moreover that a large ductile mantle weakening could originate from grain size reduction that enhances a change in the deformation mechanism from Grain Size Insensitive creep to Grain Size Sensitive creep. Such a change was described in a new mantle rheology (Hirth, 2002; Hirth and Kohlstedt, 2003; Kohlstedt, 2007) that promotes some weakening during olivine grain size reduction by enhancing the Grain Boundary Sliding in the creeping mechanisms. The consequences of this grain boundary sliding-related mechanism in natural peridotites were recently highlighted (Warren and Hirth, 2006; Précigout et al., 2007), leading us to propose that such a mechanism could affect the continental mantle strength during dynamic grain size reduction and strain localization. Therefore, we performed a one-dimensional (1-D) numerical modeling in order to quantify both the amount and the temperature conditions of strain localization due to the GBS-induced weakening. We then discussed the implications of such a rheology in terms of lithosphere strength.

\section{MANTLE RHEOLOGY: DUCTILE WEAKENING DURING GRAIN SIZE REDUCTION}

This study accounts for a new olivine rheology that combines four ductile deformation mechanisms: dislocation creep, diffusion creep, dryGBS creep and exponential creep (Goetze, 1978; Hirth and Kohlstedt, 2003; Drury, 2005). The overall strain rate ( $)$ of an olivine aggregate is then defined as follows:

$$
\mathscr{\&}=\&_{\mathrm{dislocation}}+\&_{\mathrm{diffusion}}+\&_{\mathrm{dryGBS}}+\&_{\text {exponential }}
$$

where $\&_{\text {dislocation }}, \&_{\text {diffusion }}, \&_{\text {dryGBS }}$ and $\&_{\text {exponential }}$ are the strain rates of each deformation mechanism. According to the shear stress, grain size and temperature, the deformation mechanism 
with the highest strain rate controls the aggregate deformation. These conditions are displayed through a deformation map (Frost and Ashby, 1982) at a constant overall strain rate, which shows four grain size-stress domains: the grain size insensitive-dislocation creep field at high grain size and low stress, the grain size insensitiveexponential creep field at high stress, the grain size sensitive-diffusion creep field at low grain size and low stress and the grain size sensitive-dryGBS creep field at low grain size and medium stress (fig.1B). The flow law expressions and the rheological parameters used are listed in Table of the supplementary material.

The ductile deformation of mantle rock promotes dynamic recrystallization and hence, grain size reduction. Such recrystallization can only occur if either dislocation creep, exponential creep or dryGBS creep is the controlling deformation mechanism; diffusion creep only promotes grain growth (De Bresser et al., 2001 and references therein). Starting from a large natural grain size $(>3 \mathrm{~mm})$ at incipient strain, the initial grains of an aggregate are mainly dominated by a GSI mechanism, i.e., dislocation creep or exponential creep (fig.1B). Then, dynamic recrystallization produces small grains that reduce its mean grain size and thus, changes the activity of the deformation mechanisms. The recrystallized grains appear close to the boundary of the diffusion creep field, as shown by Drury (2005) by using experimental data. Therefore they are equally dominated by dryGBS creep and diffusion creep at low temperature and high stress and by dislocation creep and diffusion creep at high temperature and low stress (fig.1B: recrystallized grains). The recrystallized grains are consistently much weaker than the initial grains at low temperatures, whereas they have a similar strength at high temperatures. As a consequence, owing to the dominance of the dryGBS creep, the mean grain size reduction due to the growing number of recrystallized grains (fig.1B, black arrow) can promote a large weakening of a deforming aggregate at low temperature (fig.1B, grey arrow). In contrast, a large weakening is not expected at high temperatures. Therefore, at temperatures lower than $T_{\mathrm{GBS}}$, which defines the critical temperature for the dominance of dryGBS creep (Précigout et al., 2007), the dynamic grain size reduction could promote large strain localization.
A

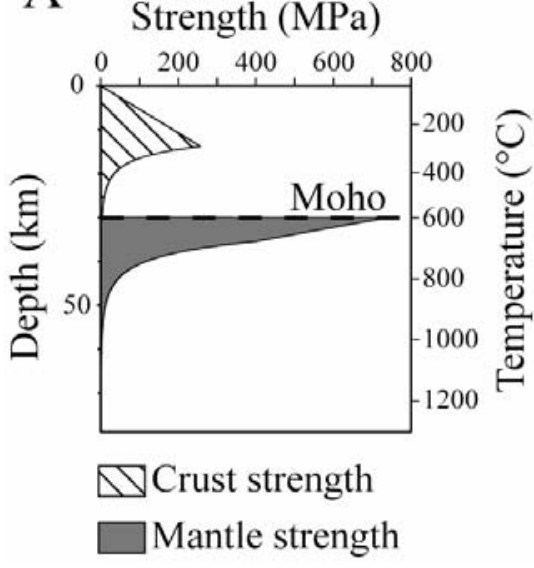

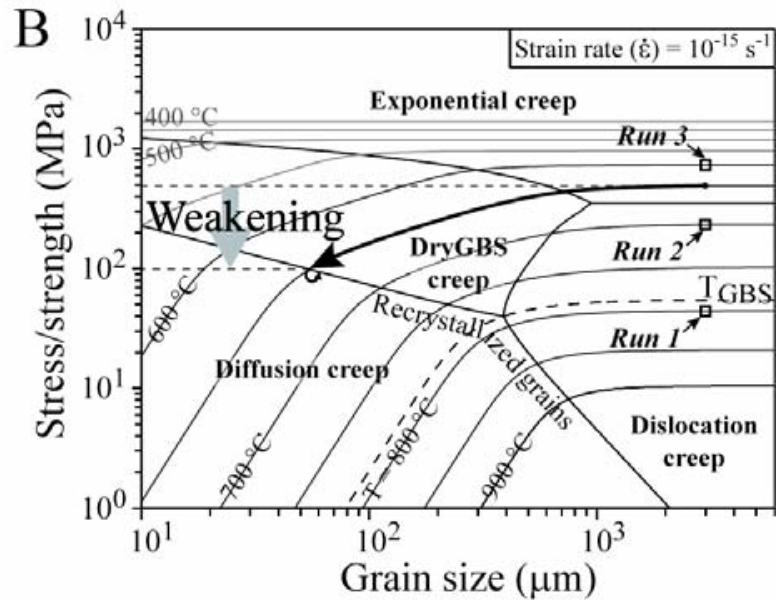

Grain size $(\mu \mathrm{m})$

FIGURE 1. A: Lithosphere strength profile with an entirely ductile continental mantle, a crustal thickness of $30 \mathrm{~km}$ and a Moho temperature $\left(T_{\mathrm{M}}\right)$ of $600{ }^{\circ} \mathrm{C}$. Rheological parameters given in the supplementary table are from Ranalli (2000), Burov and Watts (2006), Hirth and Kohlstedt (2003) and Goetze (1978) for the brittle crust, the ductile wet quartzite crust, and the ductile mantle, respectively. B: Olivine deformation map at a constant strain rate $\left(10^{-15} \mathrm{~s}^{-1}\right)$, with temperature isolines displayed every $50{ }^{\circ} \mathrm{C}$ from $900{ }^{\circ} \mathrm{C}$ to $400{ }^{\circ} \mathrm{C}$, showing the stress and grain size fields of the four olivine deformation mechanisms assumed for the mantle rheology: exponential creep, dislocation creep, dryGBS creep and diffusion creep. The mean grain size reduction of an olivine aggregate at a constant temperature (black arrow) induces weakening (grey arrow) if dynamic recrystallization occurs at a temperature lower than $T_{\mathrm{GBS}}$ (dashed isoline). At $10^{-15} \mathrm{~s}^{-1}, T_{\mathrm{GBS}}$ is equal to $787^{\circ} \mathrm{C}$ (Précigout et al., 2007). 


\section{D-MODEL: STRAIN LOCALIZATION DURING GRAIN SIZE REDUCTION}

A 1D simple shear numerical model in finitedifference approximation was performed in order to constrain the evolutions of strain rate, grain size, viscosity and stress of several olivine aggregates that compose a deforming rock at both a constant and uniform temperature (fig.2). By constraining the strain-induced relationships between all of these aggregates, this model allows the quantification of strain localization triggered by a drop in viscosity that affects either one or several olivine aggregates during dynamic recrystallization (e.g. Braun et al., 1999). We assumed a random initial distribution for the mean grain sizes of the olivine aggregates, an average of $3 \mathrm{~mm}$ (fig.2), and we simulated a dynamic grain size reduction by using the following grain size evolution law (Braun et al., 1999):

$$
d^{\mathfrak{S}}=-\delta\left(d-d_{\infty}\right) / \varepsilon_{T}
$$

where $d^{\xi}$ is the changing rate of the grain size, is the overall strain rate defined by equation (1), $d$ is the mean grain size of an olivine aggregate, $d_{\infty}$ is the recrystallized grain size defined by the field boundary hypothesis (fig.1B) and $\varepsilon_{T}$ is a constant parameter (see Montési and Hirth, 2003 and Austin and Evans, 2007 for further discussion). The initial strain rate for all of the experiments is set to $10^{-15} \mathrm{~s}^{-1}$. Through the sheared mantle rock, only the strain rate and grain size of the aggregate with the highest strain rate were extracted from the model results and plotted as a function of strain for three runs at $800{ }^{\circ} \mathrm{C}, 700{ }^{\circ} \mathrm{C}$ and $600{ }^{\circ} \mathrm{C}$ (fig. $2 \mathrm{~A}$ and 2B). We also added the grain size distribution for six strain steps in figure $2 \mathrm{~B}$. The results at $800^{\circ} \mathrm{C}$ do not show a local increase in strain rate for $200 \%$ of strain (fig.2A), and the grain size distribution is almost homogenized at the end of the experiment (fig.2B). In contrast, at $700{ }^{\circ} \mathrm{C}$, the occurrence of dryGBS creep as the controlling mechanism (fig.1B) promotes high strain localization, which increases the highest strain rate from $10^{-15}$ to almost $310^{-14} \mathrm{~s}^{-1}$. When the olivine aggregates that were affected by strain localization are completely recrystallized, the highest strain rate decreases and the strain is progressively distributed throughout the entire rock (see the supplementary material for further discussion). At $600{ }^{\circ} \mathrm{C}$, the larger
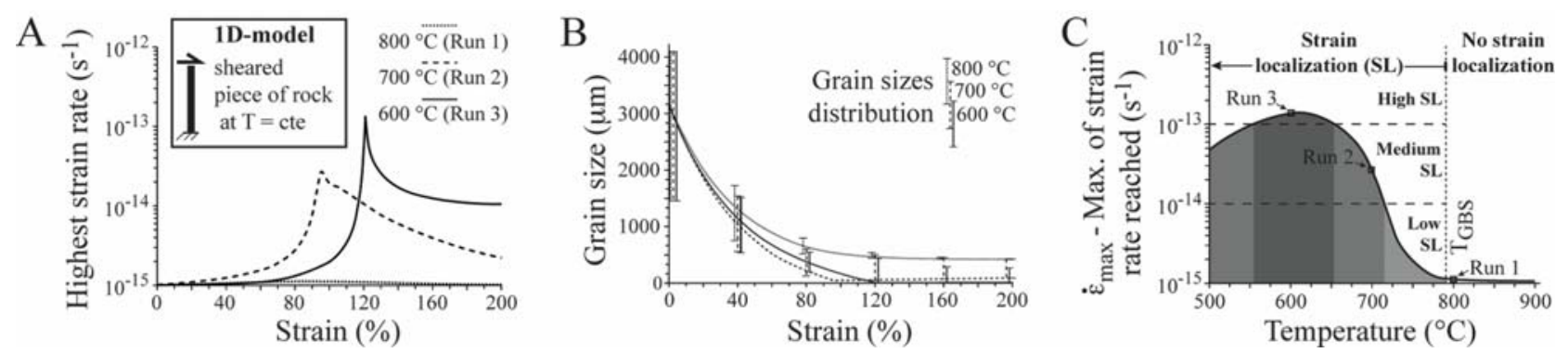

FIGURE 2. One dimensional (1-D) simple shear numerical results of several olivine aggregates at different uniform temperatures with a random initial grain size averaged at $3 \mathrm{~mm}$ (standard deviation $=375 \mu \mathrm{m}$ ). A: Evolution of the highest strain rate, in $\log$ scale, recorded through the sheared rock at $800{ }^{\circ} \mathrm{C}, 700{ }^{\circ} \mathrm{C}$ and $600{ }^{\circ} \mathrm{C}$ as a function of strain (runs 1 to 3). The initial strain rate is $10^{-15} \mathrm{~s}^{-1}$. The strength and the deformation mechanism at incipient strain for the three runs are displayed in Figure 1B. B: Evolution of both the grain size, recorded throughout the mantle rock where the strain rate is the highest, and the grain size distribution only plotted for 0, 40, 80, 120, 160 and $200 \%$ of strain. C: Maximum (max.) strain rate reached ( $\&_{\max }$, in $\log$ scale) in 32 runs at temperatures ranging from 500 to $900{ }^{\circ} \mathrm{C}$. The maximum strain rate reached for the runs 1 to 3 are plotted as three separate points. Strain localization does not occur at temperatures higher than $T_{\mathrm{GBS}}$ (dashed line) and several degrees of strain localization were defined as a function of the temperature below $T_{\mathrm{GBS}}$ : high- (dark grey), medium- (grey) and low-strain localization (light grey). See text for further details. 
weakening leads to a larger strain rate increase that reaches nearly $1.310^{-13} \mathrm{~s}^{-1}$; thereby showing the high potential of this weakening mechanism to promote strain localization. Nonetheless, the dominance of the exponential creep during grain size reduction at the beginning of the experiment (fig.1B) implies a peak of strain rate delayed with respect to the results obtained at $700{ }^{\circ} \mathrm{C}$. In addition, the conditions and the variable degrees of strain localization inferred from 32 numerical results are summarized in Figure $2 \mathrm{C}$ by plotting the maximum strain rate reached, $\underset{\max }{\stackrel{\&}{*}}$, as a function of temperature. Strain localization occurs below $787{ }^{\circ} \mathrm{C}\left(T_{\mathrm{GBS}}\right)$ and $\stackrel{\&}{\max }$ increases with decreasing temperature until $610{ }^{\circ} \mathrm{C}$. The decrease of $\underset{\max }{\&}$ at lower temperatures is also due to the primary dominance of the exponential creep. Three degrees of strain localization can thus be defined (fig 2C): $1 /$ a high strain localization $\left(\stackrel{\&}{\&}>10^{-13} \mathrm{~s}^{-1}\right)$ at temperatures between $550{ }^{\circ} \mathrm{C}$ and $650{ }^{\circ} \mathrm{C}, 2 / \mathrm{a}$ medium strain localization $\left(10^{-13} \mathrm{~s}^{-1}>\underset{\max }{\&}>10^{-14} \mathrm{~s}^{-1}\right)$ at temperatures lower than $550{ }^{\circ} \mathrm{C}$ and between $650^{\circ} \mathrm{C}$ and $720^{\circ} \mathrm{C}$, and $3 /$ a low strain localization $\left(10^{-14} \mathrm{~s}^{-1}>\underset{\max }{\&}>10^{-15} \mathrm{~s}^{-1}\right)$ at temperatures between $720^{\circ} \mathrm{C}$ and $787^{\circ} \mathrm{C}\left(T_{\mathrm{GBS}}\right)$.

\section{DUCTILE LOCALIZING MANTLE AND MODES OF CONTINENTAL RIFTING}

These numerical results at a constant temperature show first, that the dominance of dryGBS creep can promote high strain localization, and second, that such strain localization is strongly temperature-dependent. At the lithosphere scale, the continental geotherm through an uppermost ductile mantle should therefore imply a localizing mantle at temperatures lower than $T_{\mathrm{GBS}}$, with several depth-dependent degrees of possible strain localization. On the lithosphere strength profile at a Moho temperature $\left(T_{\mathrm{M}}\right)$ of $600{ }^{\circ} \mathrm{C}$ and a crustal thickness of $30 \mathrm{~km}$, four mantle rheological layers can be defined with increasing depth: a sub-Moho high-localizing mantle, a medium-localizing mantle, a low-localizing mantle and a nonlocalizing mantle (fig. 3A). In contrast, the lithosphere strength profile at $T_{\mathrm{M}}=800{ }^{\circ} \mathrm{C}$ implies only a non-localizing mantle (fig.3B). Figure 3B displays the depth of the localizing mantle and its rheological layering as a function of $T_{\mathrm{M}}$. A subMoho and highly localizing mantle thus occurs for $T_{\mathrm{M}}$ values ranging between $550{ }^{\circ} \mathrm{C}$ and $650{ }^{\circ} \mathrm{C}$. In addition, with an increasing $T_{\mathrm{M}}$ above $650{ }^{\circ} \mathrm{C}$, the

\section{Localizing mantle}

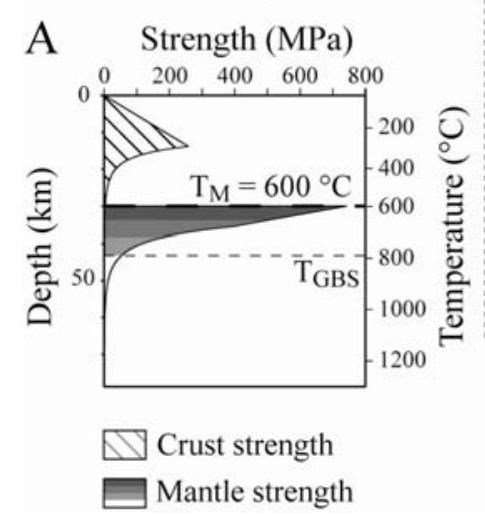

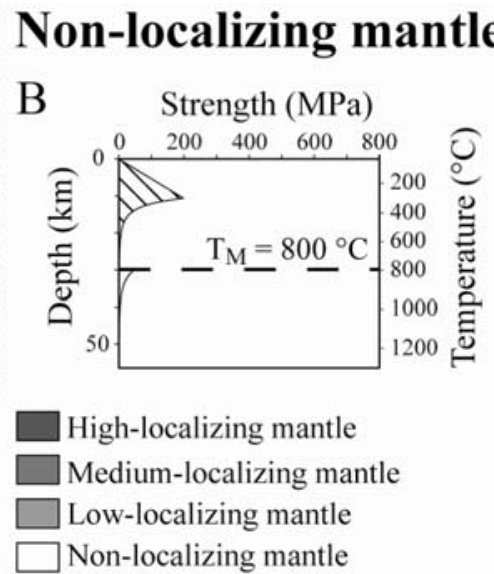
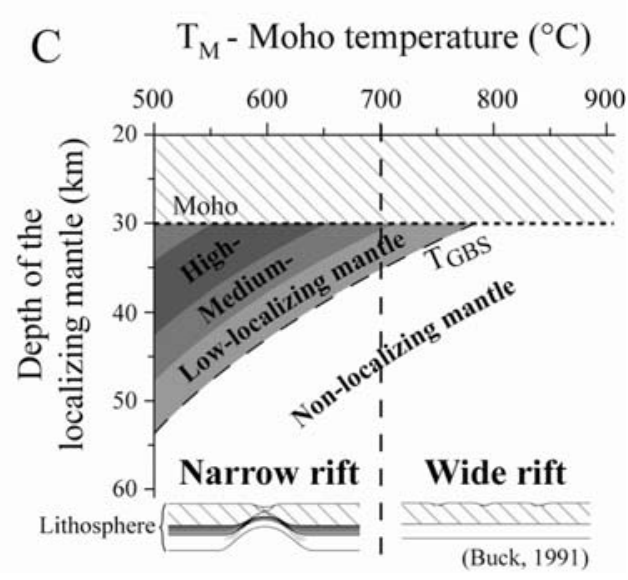

FIGURE 3. A: Lithosphere strength profiles with ductile localizing mantle at a Moho temperature $\left(T_{\mathrm{M}}\right)$ of $600{ }^{\circ} \mathrm{C}$ and $800{ }^{\circ} \mathrm{C}$, respectively, for a crustal thickness of $30 \mathrm{~km}$. Three rheological layers of localizing mantle (LM) are displayed with increasing depth: high-LM, medium-LM and low-LM. The mantle becomes non-localizing at mantle temperatures higher than $T_{\mathrm{GBS}}$. B: Lithosphere strength profile without ductile localizing mantle at Moho temperature $\left(T_{\mathrm{M}}\right)$ of $800^{\circ} \mathrm{C}$ for crustal thickness of $30 \mathrm{~km}$. C: Depth of localizing mantle and its internal rheological layering as function of Moho temperature. The relationship between critical $T_{\mathrm{M}}$ for the transition between narrow and wide rifting (dashed line, Buck 1991) and conditions for occurrence of localizing mantle are discussed in the text. 
sub-continental mantle becomes moderately localizing, then weakly localizing and finally not localizing above $T_{\mathrm{GBS}}$. Likewise, with a decreasing $T_{\mathrm{M}}$ below $550{ }^{\circ} \mathrm{C}$, the high-localizing mantle is continuously deeper and the sub-Moho mantle becomes moderately localizing.

On these bases, the variation in localizing degree for the sub-continental mantle could strongly affect the mechanical behavior of the lithosphere. Taking continental rifting as example, Buck (1991) argued that narrow rifting requires the occurrence of a strong and localizing sub-Moho mantle. Without these two lithospheric features, continental necking does not occur, which leads to wide rifting. The sub-Moho brittle mantle is commonly invoked as this strong and localizing layer, and implies a transition between a narrow rift and wide rift at $T_{\mathrm{M}}$ $=700{ }^{\circ} \mathrm{C}$ (Buck 1991). However, this latter case does not match several geological/geophysical data and therefore led us to propose an entirely ductile mantle featured by the localizing mantle. In order to justify this proposition, the thermal conditions for the occurrence of a localizing mantle are compared to those defining the modes of continental rifting (fig.3C). For all $T_{\mathrm{M}}$ values below $700{ }^{\circ} \mathrm{C}$ that predict a narrow rift, a mediumor a high-localizing mantle occurs beneath the crust, whereas only a low- or a non-localizing mantle occurs in wide rifting conditions. We therefore propose that such a ductile localizing rheology could replace the brittle mantle in order to explain lithosphere-scale strain localization. Consistently, for $T_{\mathrm{M}}$ values lower than $500{ }^{\circ} \mathrm{C}$, the deep and high-localizing mantle, and the very low temperature of the sub-continental mantle, which inhibits strain localization, could explain why cratons remain both undeformed and very stable (e.g. Lenardic et al., 2003).

\section{IMPLICATIONS OF THE DUCTILE LOCALIZING MANTLE FOR LONG- TERM LITHOSPHERE DEFORMATION}

Both the dynamic and the elastic thickness of the lithosphere require a "jelly sandwich" model for lithosphere strength, with a mantle stronger than the crust. However, a "crème brûlée" model, with a mantle weaker than the crust, is predicted beneath deforming regions. We assumed here an entirely ductile mantle featured by a temperaturedependent localizing mantle able to promote large strain localization during grain size reduction. Such a localizing mantle could replace the brittle mantle as a large-scale localizing mechanism and hence, could so imply a decrease in the mantle strength during ductile strain localization. Indeed, in a forming peridotite shear zone, dynamic grain size reduction and subsequent intense strain localization leads to a nearly complete dynamic recrystallization. The intrinsic strength of such a shear zone can be thus estimated according to the stress-grain size relationship for the recrystallized grains (fig.1A and 4A). At temperatures lower than $T_{\mathrm{GBS}}\left(787^{\circ} \mathrm{C}\right)$, the recrystallized grains are much weaker than the undeformed grains. Therefore, during large-scale deformation and strain localization, a decrease in the uppermost mantle strength could occur in a mantle shear zone from an initial strength, defined by a grain size insensitive mechanism, to the strain-coeval strength of the recrystallized grains (fig.4A). As a consequence, the long-term deformation of the lithosphere could change the mantle/crust strength ratio in a lithosphere-scale shear zone from a mantle-dominated strength, i.e., the "jelly sandwich" model, to a crust-dominated strength, i.e., the "crème brûlée" model (fig.4B). The weak mantle strength predicted beneath deforming regions from geological and geophysical data could therefore be a consequence of both longterm deformation $\left(\geq 10^{6} \mathrm{yr}\right)$ and large-scale strain 
Lithosphere strength

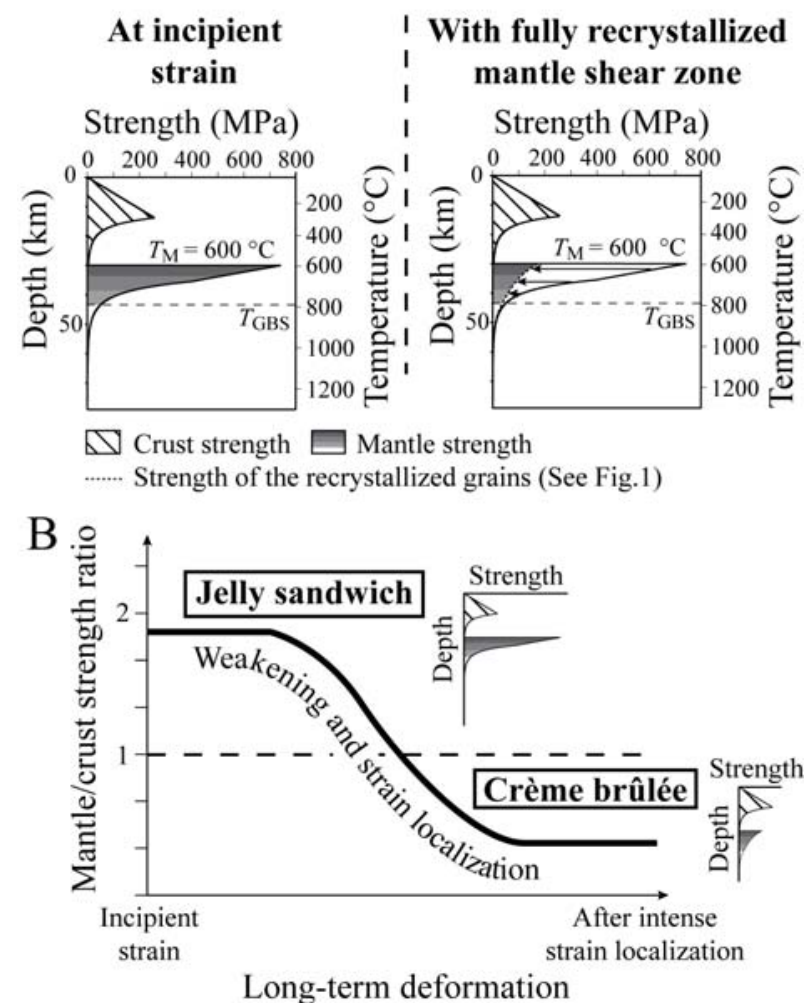

localization, and might not only reflect a steadystate strength of the lithosphere.

\section{ACKNOWLEDGMENTS}

This study was supported by the DyetiINSU/CNRS (Institut National des Sciences de l'Univers/Centre National de la Recherche Scientifique) project. We thank Laurent Husson for his useful comments and Laurent Montési and an anonymous reviewer for their constructive remarks.

\section{REFERENCES CITED}

Austin, N. J., and Evans, B., 2007, Paleowattmeters: A scaling relation for dynamically recrystallized grain size: Geology, v. 35, p. 343-346.

Brace, W.F., and Kohlstedt, D.L., 1980, Limits on Lithospheric Stress Imposed by Laboratory Experiments: Journal of Geophysical Research, v. 85 , p. 6248-6252.
FIGURE 4. Implications of the grain boundary sliding-induced strain localization on the long-term strength of the continental lithosphere. A: Lithosphere strength profiles with large mantle grain size at incipient strain (left side) and after complete dynamic recrystallization within mantle shear zone (right side). The three rheological layers of localizing mantle are displayed with the grey shading defined in Figure 3. At sub-Moho depths, the fully recrystallized mantle shear zone is significantly weaker than the initial mantle due to the large weakening and subsequent strain localization, which occurs during grain size reduction at temperatures lower than $T_{\mathrm{GBS}}$ (black arrows). B: Mantle/crust strength ratio during longterm deformation. Weakening in mantle shear zones due to grain boundary sliding-induced strain localization could change the lithosphere strength layering from the "jelly sandwich" model to the "crème brûlée" model in deforming regions.

Braun, J., Chéry, J., Poliakov, A., Mainprice, D., Vauchez, A., Tommasi, A., and Daignière, M., 1999, A simple parameterization of strain localization in the ductile regime due to grain size reduction: a case study for olivine: Journal of Geophysical Research, v. $104 \mathrm{~N}^{\circ} \mathrm{B} 11$, p. 25,16725,181 .

Brun, J.P., 2002, Deformation of the continental lithosphere: Insights form brittle-ductile models. in deMeer, S., deBresser, J.H.P., Pennock, G.M. (Eds.), Deformation Mechanisms, Rheology and Tectonics: Current Status and Future Perspectives. Geological Society of London Special Publications 200, p. 355-370.

Buck, W.R., 1991, Modes of continental Lithospheric Extension: Journal of Geophysical Research, v. 96, p. 20,161-20,178.

Burov, E.B., and Diament, M., 1995, The effective elastic thickness (Te) of continental lithosphere: what does it really mean?: Journal of Geophysical Research, v. 100, p. 3905-3927.

Burov, E.B., and Watts, A.B., 2006, The long-term strength of continental lithosphere: "jelly sandwich" or "crème brûlée"?: GSA Today, v. 16, p. 4-10.

De Bresser, J.H.P., Ter Heege, J.H., and Spiers, C.J., 2001, Grain size reduction by dynamic recrystallization: can it result in major rheological 
weakening?: International Journal of Earth Sciences, v. 90, p. 28-45.

Drury, M.R., 2005, Dynamic recrystallization and Strain Softening of Olivine Aggregates in the Laboratory and the Lithosphere: in Gapais, D., Brun, J.P. and Cobbold, P.R. (eds) Deformation Mechanisms, Rheology and Tectonics: from Minerals to the Lithosphere: Geological Society, London, Special Publications, v. 243, p. 127-142.

Drury, M.R., Vissers, R.L.M., Van Der Wal, D., and Hoogerduijn strating, E.H., 1991, Shear localisation in Upper Mantle Peridotites: Pure and Applied Geophysics, v. 137, p. 439-460.

Frost, H.J., and Ashby, M.F., 1982, Deformation Mechanism Maps: the Plasticity and Creep of Metals and Ceramics: Oxford, Pergamon Press, $184 \mathrm{p}$.

Goetze, C., 1978, The mechanisms of creep in olivine: Philosophical Transactions of the Royal Society London Series A, v. 288, p. 99-119.

Gueydan, F., Morency, C. and Brun, J.-P., 2008, Continental rifting as a function of lithosphere mantle strength: Tectonophysics, doi:10.1016/j.tecto.2008.08.012

Handy, M.R., and Brun, J.P., 2004, Seismicity, structure and strength of the continental lithosphere: Earth and Planetary Science Letters, v. 223, p. 427-441.

Hirth, G., 2002, Laboratory constraints on the rheology of the upper mantle: in Karato S-I and Wenk H-R (eds.) Plastic Deformation in Minerals and Rocks: Reviews in Mineralogy and Geochemistry, v. 51, p. 97-120.

Hirth, G., and Kohlstedt, D., 2003, Rheology of the Upper Mantle and the Mantle Wedge: A view from the Experimentalists: in Eiler, J. (ed) Inside the subduction factory: Geophysical Monographs, v. 138, p. 83-105.

Jackson, J., 2002, Strength of the continental lithosphere: Time to abandon the jelly sandwich?: GSA Today, v. 12, p. 4-10.

Kohlstedt, D. L., 2007, Properties of rocks and minerals Constitutive equations, rheological behavior, and viscosity of rocks: in Schubert, G. (ed) Treatise on Geophysics, v. 2.14, p. 389-417.
Lenardic, A., Moresi, L.-N., and Mühlhaus, H., 2003, Longevity and stability of cratonic lithosphere: Insights from numerical simulations of coupled mantle convection and continental tectonics: Journal of Geophysical Research, v. 108, 2303, doi:10.1029/2002JB001859.

Maggi, A., Jackson, J.A., McKenzie, D., and Priestley, K., 2000, Earthquake focal depths, effective elastic thickness, and the strength of the continental lithosphere: Geology, v. 28, p. 495-498.

Montési, L. G. J., and Hirth, G., 2003, Grain size evolution and the rheology of ductile shear zones: from laboratory experiments to postseismic creep: Earth and Planetary Science Letters, v. 211, p. 97110.

Précigout, J., Gueydan, F., Gapais, D., Garrido, C.J., and Essaifi, A., 2007, Strain localisation in the subcontinental mantle - a ductile alternative to the brittle mantle: Tectonophysics, v. 445, p. 318-336.

Ranalli, G., 2000, Rheology of the crust and its role in tectonic reactivation: Journal of Geodynamics, v. 30, p. 3-15.

Ranalli, G., and Murphy, D.C., 1987, Rheological stratification of the lithosphere: Tectonophysics, v. 132, p. 281-295.

Rutter, E.H., and Brodie, K.H., 1988, The role of tectonic grain size reduction in the rheological stratification of the lithosphere: International Journal of Earth Sciences, v. 77, p. 295-307.

Thatcher, W., and Pollitz, F.F., 2008, Temporal evolution of continental lithospheric strength in actively deforming regions: GSA Today, v. 18, p. 4-11.

Warren, J.M., and Hirth, G., 2006, Grain size sensitive deformation mechanisms in naturally deformed peridotites: Earth and Planetary Science Letters, v. 248, p. 423-435. 


\begin{tabular}{|c|c|c|c|}
\hline \multicolumn{4}{|c|}{ A Strength profile } \\
\hline \multicolumn{4}{|c|}{ Overall parameters } \\
\hline \multirow{2}{*}{\multicolumn{2}{|c|}{ (1) $\rho$-Rock density $\left(\mathrm{kg} \cdot \mathrm{m}^{3}\right)$}} & Crust & Mantle \\
\hline & & 2800 & 3330 \\
\hline \multicolumn{2}{|c|}{ (1)Thermal conductivity $\left(\mathrm{W} \cdot \mathrm{m}^{-1} \cdot \mathrm{K}^{-1}\right)$} & 2,5 & 3,0 \\
\hline \multicolumn{2}{|c|}{ Thickness (m) } & 30000 & - \\
\hline \multicolumn{2}{|c|}{ g-Gravitational acceleration $\left(\mathrm{m} \cdot \mathrm{s}^{-2}\right)$} & \multicolumn{2}{|c|}{9,81} \\
\hline \multicolumn{2}{|c|}{ R-Universal gas constant $\left(\mathrm{J} \cdot \mathrm{mol}^{-1} \cdot \mathrm{K}^{-1}\right)$} & \multicolumn{2}{|c|}{8,314} \\
\hline \multicolumn{2}{|c|}{$\dot{\varepsilon}$-Overall strain rate $\left(\mathrm{s}^{-1}\right)$} & \multicolumn{2}{|c|}{$1.10^{-15}$} \\
\hline \multicolumn{2}{|c|}{$\begin{array}{l}\text { (1) Crustal Radioactive heat } \\
\text { production }\left(\mathrm{W} \cdot \mathrm{m}^{-3}\right)\end{array}$} & \multicolumn{2}{|c|}{$r=r 0 \cdot \exp (-z / H r)$} \\
\hline With & \multicolumn{3}{|c|}{$\begin{array}{l}\mathrm{r} 0\left(\mathrm{~W} \cdot \mathrm{m}^{-3}\right)=2,565 \cdot 10^{-6} ; \mathrm{z}(\mathrm{m})=\text { depth; } \\
\mathrm{Hr}(\mathrm{m})=10000\end{array}$} \\
\hline
\end{tabular}

\begin{tabular}{|c|c|c|c|}
\hline \multicolumn{4}{|l|}{ Brittle rheology } \\
\hline \multirow{2}{*}{ (2) Strength (MPa) } & \multirow{2}{*}{\multicolumn{3}{|c|}{$\tau_{\text {brittle }}=\frac{(2 \cdot \mu \cdot \rho \cdot g \cdot z)^{*}(1-\lambda)}{\left(\mu^{2}+1\right)^{1 / 2}+\mu} \cdot 10^{-6}$}} \\
\hline & & & \\
\hline \multicolumn{4}{|c|}{ With $\quad \mu$ (sliding coef. $)=0,6 ; \lambda$ (pore pressure $)=0$. } \\
\hline \multicolumn{4}{|l|}{ Ductile rheology } \\
\hline \multicolumn{4}{|c|}{${ }^{1} \tau_{\text {ductile }}(<200 \mathrm{Mpa})=\dot{\varepsilon}^{(1 / n)} \cdot \mathrm{A}^{(-1 / \mathrm{n})} \cdot \exp [\mathrm{Q} /(\mathrm{n} . \mathrm{R} . \mathrm{T})]$} \\
\hline \multicolumn{4}{|c|}{${ }^{2]} \boldsymbol{\tau}_{\text {ductile }}(>200 \mathrm{Mpa})=\left[1-(\ln (\mathrm{A} / \dot{\varepsilon}) \cdot \mathrm{R} \cdot \mathrm{T} / \mathrm{Q})^{(1 / n)}\right] \cdot 8500$} \\
\hline \multirow{2}{*}{ 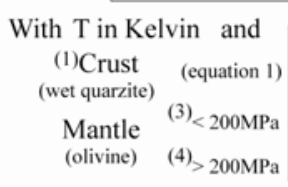 } & $\left|\begin{array}{c}\mathrm{A}\left(\mathrm{MPa}^{-\mathrm{n}} \cdot \mathrm{s}^{-1}\right) \\
1,1.10^{4}\end{array}\right|$ & $\begin{array}{l}\mathrm{Q}\left(\mathrm{J} . \mathrm{mol}^{-1}\right) \\
223.10^{3}\end{array}$ & \\
\hline & $\begin{array}{c}1,1 \cdot 10^{5} \\
5,7 \cdot 10^{11}\left(\mathrm{~s}^{-1}\right)\end{array}$ & $\begin{array}{l}530.10^{3} \\
535.10^{3}\end{array}$ & $\begin{array}{c}3,5 \\
2\end{array}$ \\
\hline
\end{tabular}

\section{B Deformation map}

\begin{tabular}{|c|c|c|c|c|c|}
\hline \multicolumn{6}{|l|}{ Flow laws } \\
\hline \multicolumn{6}{|c|}{ 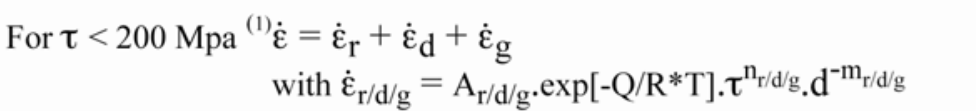 } \\
\hline \multicolumn{6}{|c|}{$\begin{aligned} \text { For } \tau>200 \mathrm{Mpa}^{(3)} \dot{\varepsilon}=\dot{\varepsilon}_{\mathrm{r}}+\dot{\varepsilon}_{\mathrm{d}}+\dot{\varepsilon}_{\mathrm{g}}+\dot{\varepsilon}_{\mathrm{e}} \\
\\
\text { with }{ }^{(2)} \dot{\varepsilon}_{\mathrm{e}}=\mathrm{A}_{\mathrm{e}} \cdot \exp \left[-\left(\mathrm{Q} / \mathrm{R}^{*} \mathrm{~T}\right) \cdot\left(1-\tau / \tau_{\mathrm{p}}\right)^{\mathrm{n}_{\mathrm{e}}}\right]\end{aligned}$} \\
\hline Parameters & $\begin{array}{l}\mathrm{A}\left(\mathrm{MPa}^{-\mathrm{n}} \cdot \mathrm{s}^{-1}\right) \\
\text { pre-exponential } \\
\text { constant }\end{array}$ & $\begin{array}{l}\mathrm{Q}\left(\mathrm{J} . \mathrm{mol}^{-1}\right) \\
\text { Activation } \\
\text { energy }\end{array}$ & $\begin{array}{c}\mathrm{n} \\
\text { Stress } \\
\text { exponent }\end{array}$ & $\begin{array}{c}\mathrm{m} \\
\text { Grain size } \\
\text { exponent }\end{array}$ & $\begin{array}{c}\tau_{\mathrm{p}} \\
\text { Goetze's } \\
\text { constant }\end{array}$ \\
\hline (1)(Dry)-Dislocation creep (r) & $1,1.10^{5}$ & $530.10^{3}$ & 3,5 & - & - \\
\hline (1)(Dry)-Diffusion creep (d) & $1,5.10^{9}$ & $375.10^{3}$ & 1 & 3 & - \\
\hline (1)DryGBS creep (g) & $6,5 \cdot 10^{3}$ & $400.10^{3}$ & 3,5 & 2 & - \\
\hline (2) Exponential creep (e) & $5,7.10^{11}\left(\mathrm{~s}^{-1}\right)$ & $535.10^{3}$ & 2 & - & 8500 \\
\hline
\end{tabular}

TABLE. A: Constant and parameter values used to construct the lithosphere strength profiles. B: Flow laws and creep parameters of the four olivine deformation mechanisms from Goetze (1978) and Hirth and Kohlstedt (2003). These flow laws are used to construct the deformation map displayed in Figure 1B (Drury, 2005; Précigout et al., 2007). 

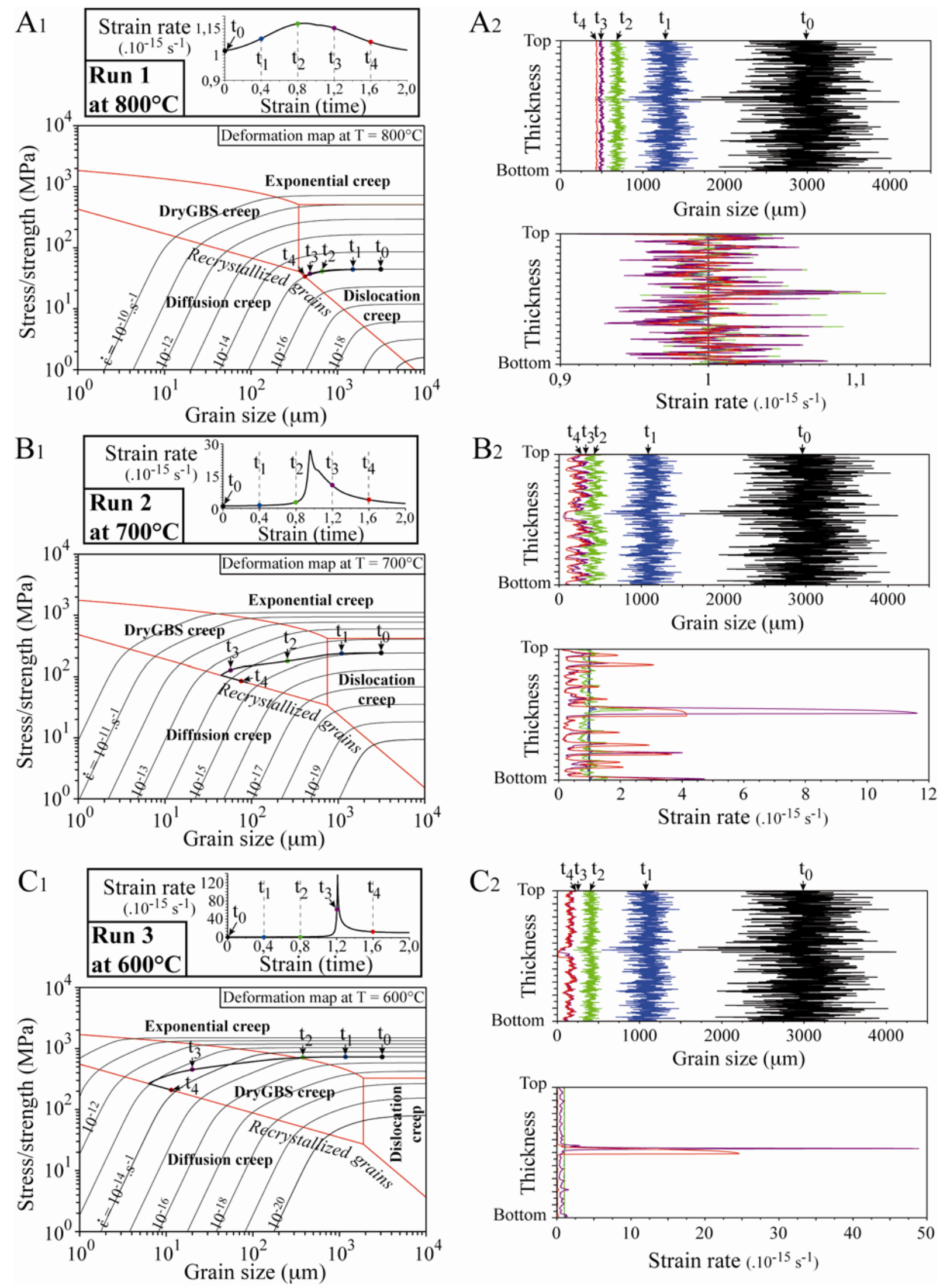

MODELING RESULTS. 1-D numerical results at three different temperatures $\left(800{ }^{\circ} \mathrm{C}, 700{ }^{\circ} \mathrm{C}\right.$ and $600{ }^{\circ} \mathrm{C}$, from top to bottom) that show first, the highest strain rate recorded within the sheared rock as a function of strain, second, a deformation map at a given temperature, and third, both grain size and strain rate distributions within the sheared rock at five strain steps. The stress/grain size path of the olivine aggregates 
with the highest strain rate was plotted on the deformation maps in order to document the controlling deformation mechanism during dynamic recrystallization. The mean grain size and strain rate of the five strain steps are also reported in the deformation maps and the strain rate-strain curves. The 1D numerical model was performed using the "finite-difference approximation" for the sheared rock divided into 800 nodes. One node represents an olivine aggregate that is mainly deformed by either dislocation creep, diffusion creep, dryGBS creep or exponential creep, according to its mean grain size, strain rate and shear stress. During the experiment, the strain rate/stress and grain size were thus calculated at each node based on the mechanical equilibrium (constant shear stress throughout the rock). The initial strain rate through the mantle rock was set to $10^{-15} \mathrm{~s}^{-1}$ and the results are displayed as dimensionless. The initial grain size distribution throughout the mantle rock is characterized by a random grain size averaged at $3 \mathrm{~mm}$ with a standard deviation of $375 \mu \mathrm{m}$ (Figure A2, strain step $\mathrm{t}_{0}$ ). A: Modeling results at $800{ }^{\circ} \mathrm{C}$. A1: Time evolution of the maximum strain rate recorded, to which we added five strain steps (colored dots at 0, 0.4, 0.8, 1.2 and 1.6 strain), in order to illustrate the evolution of both grain size and strain rate distributions in the rock. A2: Distributions of both the mean grain size and the strain rate of all of the olivine aggregates. Such distributions are displayed for the five aforementioned strain steps according to their own specific color. These results show that the deformation of the olivine aggregate at $800{ }^{\circ} \mathrm{C}$ is never accommodated by dryGBS creep during dynamic grain size reduction. As a consequence, the GBS-induced weakening does not occur and there is not a local increase in strain rate, i.e., there is no strain localization (fig.A2). B: Modeling results at $700{ }^{\circ} \mathrm{C}$. Unlike the results at $800{ }^{\circ} \mathrm{C}$, some of the olivine aggregates (the smallest) become dominated by dryGBS creep during their mean grain size reduction (deformation map in B1). As a consequence, some weakening occurs during dynamic recrystallization and strain localization is triggered, i.e., one major peak in strain rate within a thin area of the sheared rock (step $t_{3}$ in B2) is observed between strain steps $t_{2}$ and $t_{3}(B 1)$. The mean grain size in this forming shear zone then rapidly reaches the balance of the recrystallized grains (deformation map in B1), involving several olivine aggregates with $100 \%$ of recrystallized grains (B2). Thus, dynamic recrystallization is complete in these aggregates, leading to the inhibition of the strain localization process in this area and to the redistribution of the strain rate throughout the rock (step $t_{3}$ to $t_{4}$ in B2). This feature explains the decrease in strain rate within the shear zone that occurs at the end of the experiment, between strain steps $t_{3}$ and $t_{4}$. C: Modeling results at $600{ }^{\circ} \mathrm{C}$. The dominance of exponential creep on the olivine aggregates during the early stage of deformation (strain steps from $t_{0}$ to $t_{2}$ in C1) delays the strain localization process, which affects the smallest mean grain size. Despite this feature, the weakening implied by dryGBS creep for the recrystallized grains is larger than the weakening at $700{ }^{\circ} \mathrm{C}$ and thus promotes a higher local strain rate increase, i.e., the strain rate has increased by a factor of 50 within a single node at strain step $t_{3}(\mathrm{C} 2)$. As a consequence, the width of this shear zone that localizes strain is thinner than that at $700{ }^{\circ} \mathrm{C}(\mathrm{B} 2$ and $\mathrm{C} 2)$. 